\title{
TO CARE OR NOT TO CARE - REFLECTIONS ON THE ETHICS OF BLENDED LEARNING IN TIMES OF DISRUPTION
}

\section{B. C. Swartz*}

Department of Industrial and Systems Engineering

e-mail: swartzb@cput.ac.za

\section{Gachago*}

Centre for Innovative Educational Technology

e-mail: gachagod@cput.ac.za

\section{Belford*}

Department of Civil Engineering

e-mail: Belfordc@cput.ac.za

${ }^{*}$ Cape Peninsula University of Technology

Cape Town, South Africa

\section{ABSTRACT}

The recent student protests in South African Higher Education have highlighted both the opportunities and challenges of blended/online learning in higher education. This article describes two lecturers' attempts at continuing teaching online during the 2016 campus closure at a large University of Technology in South Africa. Using Tronto's Ethics of Care lens and in particular her moral characteristics of care, namely attentiveness, responsibility, competence, responsiveness and solidarity, we reflect on the ethics of our practices when moving towards more open educational practices. Recommendations on academic staff development that promotes ethical open practices conclude the article.

Keywords: blended learning, open learning, online learning, ethics, disruption, student protests, ethics of care, Higher Education, South Africa, open educational practices

\section{INTRODUCTION}

Openness is a key concern in recent times in Higher Education (HE) (Gil-Jaurena 2013) since on a global level, open access, open educational resources (OER), massive online courses (MOOCs) and related interests have become "hot topics". Openness in education has also received increasing focus in the South (Cox and Trotter 2016). This study is based at a University of Technology (UoT) in South Africa, which services a large number of underprivileged students. Both students and the institution itself operate within serious limitations in terms of personal and financial resources. In this context, open practices such as 
the provision of access to OER or the use of participatory technologies such as social media or instant messaging, are promoted as viable solutions for the on-going challenge of providing an affordable, quality educational experience (Bozalek, Ng'ambi and Gachago 2013; Gachago et al. 2013). Recent institutional policy developments, such as the open access policy driving an open research agenda or the OER policy (under development) show a movement towards openness at the institution.

The interest in openness spiked during the recent 2015 and 2016 Fees Must Fall student protests (\#FMF), which highlighted the continuing inequalities impacting on students' access and success in higher education. The countrywide closure of campuses led to a sudden surge in online learning to continue the academic project off campus. An increased interest in both institutional technologies, such as the learning management system (LMS), but also open technologies, such as social media or the Google application suite, was noted as lecturers desperately attempted to salvage an academic semester disrupted mid-way.

Whether or not to continue teaching and completing the academic year was a decision left to Faculties, Departments and even individual lecturers. Campus closures translated into the halt of teaching for many lecturers, unless they had already established alternative strategies of content delivery, communication with students and assessment. However, as more and more lectures moved their teaching online, questions around the ethics of using open learning to support our students during and beyond campus shutdowns, became paramount. While the prevalent literature on the ethics of blended or open learning focuses predominantly on academic integrity and honesty, the ethics of continuing the academic project during times of disruption extended beyond questions of how to organise online assessments off campus. Issues of unequal access to the resources which is critical for online learning, and one of the basic tenets of the student protests, were hotly debated. Was it fair to offer online learning to students who might or might not be able to afford it and might or might not have the digital literacies needed to engage in online learning? Should it be offered on a voluntary basis? Continuing the academic project therefore meant taking a political stance against the demands of the student movement. What would that mean for the students involved? Did it force them to compromise their academic and political identity? Equally important, did it put their personal security at risk?

Following authors such as Anderson and Simpson (2007) and Reamer (2013) who see ethics as more than academic integrity and include access, power and difference as ethical concerns, we will reflect in this article on the process and the learning that we - as a collective of academics and academic staff developers who met through an institutional OER project could draw from moving our teaching into an open space during and beyond the student protests 
including our growing interest and concern around the ethics of our teaching. We found Tronto's Ethics of Care qualities $(1993 ; 2013)$, which sees ethics as something we do, rather than based on fixed values, as a practice, helpful as an overarching thinking tool to unpack the ethics of our own practices.

\section{THE ETHICS OF BLENDED / ONLINE / OPEN LEARNING}

To reflect on the ethics of our teaching practices we employ Joan Tronto's ethics of care framework $(1993 ; 2013)$. Tronto positions care as a political project and argues that care is not just a disposition but an active ethical practice - not something we are but something we $d o$. Rather than seeing ethical dilemmas as big - and often unsolvable - questions, it is in our everyday practices of caring for ourselves and others that we most need to consider and practice ethical behaviour (Tronto 2001). Fisher and Tronto $(1990,40)$ define care as "a species activity that includes everything that we do to maintain, continue, and repair our 'world' so that we can live in it as well as possible. That world includes our bodies, ourselves, and our environment, all of which we seek to interweave in a complex, life-sustaining web." Tronto is very clear that not all care is good care. As yardsticks against which to compare our care practices, she initially defined four (1993) and then five (2013) moral elements of care and their respective phases (in brackets):

1. Attentiveness (caring about): noticing unmet needs, suspending one's own judgements and being able to see the world from the perspective of the one in need.

2. Responsibility (caring for): taking on the burden of responding to this need.

3. Competence (care giving): being competent to care, which is always both a technical and a moral and political issue.

4. Responsiveness (care receiving): listening to the response of the person/group that was cared for, sometimes resulting in new unmet needs.

5. Solidarity (caring with): taking collective responsibility, to think of citizens as both receivers and givers of care, and to think seriously about the nature of caring needs in society.

In order to think about the ethics of open / blended / online learning, we need to first define these terms. Online learning is learning that is exclusively online without any face-to-face interaction. Given the variety of ways in which the terms "blended", "flexible" or "distance" education are used, they have become elusive concepts to write about, both from a theoretical and a practical point of view. At our institution blended learning is defined as any learning 
which involves a mix of face-to-face and online learning, depending on context, learners and content. As such we follow authors such as Krause's (cited in Bath and Bourke 2010), who argues that " $[\mathrm{b}]$ lended learning is realised in teaching and learning environments where there is an effective integration of different modes of delivery, models of teaching and styles of learning as a result of adopting a strategic and systematic approach to the use of technology combined with the best features of face to face interaction". Blending refers to time (synchronous vs asynchronous), people (lecturers/experts), location (on campus/off campus, face to face/online), resources (textbooks, online resources, audio, video etc.) and communication/collaboration (in class/out of class vs face to face/online). Blended learning can then accommodate a variety of learning experiences both on- and off-campus, with a varying amount of "distance" between learners and lecturers. While our institution is inherently a contact institution, it faces an increasing need to incorporate a blended educational model to adapt to changing (and often unpredictable) times (Centre for Innovative Educational Technology 2016).

Blended learning is defined as open when the institutional boundaries of learning become permeable by for example using OER or sharing learning materials on open platforms beyond institutional learning management systems and platforms such as YouTube (Cronin 2017). Following Cronin $(2017,4)$ we define Open Educational Practices (OEP) as "collaborative practices which include the creation, use and reuse of OER, as well as pedagogical practices employing participatory technologies and social networks for interaction, peer-learning, knowledge creation, and empowerment of learners". Thus blended learning can encompass OEP but OEP is not necessarily blended as they can be exclusively online as well.

Literature seems to concur that online/blended/open learning amplifies ethical issues traditionally encountered in face-to-face education (Anderson and Simpson 2007). However, it also gives rise to a substantial amount of new issues (Collins 2016; Reamer 2013). Most literature related to the ethics of blended or online learning seems to focus on academic integrity or honesty (Brown 2008, Coleman 2011, McMahon 2007, Meine, Dunn and Abbey 2012), often linked to the "psychological distance" (Savin 1992 cited in Brown 2008) online learners experience, which seemingly makes it easier to "cheat". Coleman (2011) for example focuses entirely on issues around assessing students' work and responsibilities of students, academic staff and administration in ensuring ethical behaviour when it comes to assessment. Brown (2008) differentiates ethical concerns in online learning in concerns for students - linked to academic fraud, and concern for teachers - linked to maintaining quality of learning and learning materials and ensuring that no academic fraud is being committed. He mentions the importance of providing a stable infrastructure with appropriate copyright policies and lists 
network security and safety issues as ethical concerns.

Anderson and Simpson's 2007 article - while dated - may still be one of the most relevant reflections on the ethics of offering online learning for our own context. They also touch on issues around surveillance, consent, identity, confidentiality and anonymity with regards to online assessment and engagement; however their focus on access, cultural impacts and power resonate much more with our own experience with offering blended learning. Their position that online learning is distance learning with restricted access is an essential one, as it points to the importance of considering issues of access in particular when dealing with economically disadvantaged students. More recent research into MOOCs reaffirm the notion that online learning needs considerable digital literacies and resources and is "not for all" (Czerniewicz et al. 2016). Anderson and Simpson's (2007) discussion of the cultural practices of learners and how they impact online engagement is another important reminder to recognise our learners are on different levels of participation online and offline, and how learner practices may influence their engagement and success in different learning contexts. This leads to important questions around learner support and assessment practices. What counts as participation face-to-face and online? Anderson and Simpson (2007) also ask important questions around power dynamics in online contexts, both in terms of lecturer-student relationship but also about students themselves. Who speaks out in an online discussion forum? Who is intimidated? This is highly relevant in our context, where finding alternative ways to continue the academic project was perceived as undermining the student protests, which in some cases lead to threats of violence for students who quietly or openly challenged the movement. Students were dragged out of classrooms, books and devices were taken away and other mechanisms were used to halt any academic engagement.

Finally, Hanson (2009) maintains that for academic staff, the increased prominence given to blended learning in universities, not only results in a transformation in their teaching practices but also has an implication on their development as academics and their view of "self". How lecturers respond to the ethical issues of blended learning mentioned above undoubtedly have a role to play during this transformation. As we will argue throughout the article, we construe openness as a practice rather than resources or a project. This means that openness has to manifest itself in the culture of an institution, in the ways we teach and in the way our students learn. Wenger, McDermott and Snyder (2002) argue that a community of practice, which we include ourselves as members of an OER project, embodies a certain way of behaving, a perspective on problems and ideas, a thinking style, and even an ethical stance, continuously renegotiated as an ethical practice among all stakeholders involved in an academic project. As such for this article using the ethics of care as normative framework will allow us to go beyond 
individual issues around ethics such as academic integrity and even access to allow us an indepth contextual analysis of our practice but also how our decisions impact on our academic identities, both as individual and as a community of practice.

\section{METHODOLOGY}

A constructivist and interpretivist epistemology served as the framework for our research (Probst 2016). The research approach that was adopted is described by Probst $(2016,149)$ as "unusual" by virtue of researchers holding dual roles of providing research data and analysing the data themselves. Probst (2016) offers the merit of researchers' taking the place of participant in that it is an approach which fosters richer meanings of research findings through reflexivity, an appreciation for mutuality and the co-construction of knowledge that cannot be learned by simply reading about it. She opines that this practice adds value due to its capacity to foster ethical conduct, thereby endorsing the orientation of our case studies.

Both Cheryl and Bronwyn are lecturers in the Faculty of Engineering. Cheryl lectures at the exit level in the undergraduate programme in the Department of Civil Engineering while Bronwyn teaches statistics to final year students and to first year students in the Department of Industrial and Systems Engineering. Both have been using blended learning for some years to help students cope with the volume of content they need to cover in their courses by providing them with pre-lecture resources such as PowerPoint and pre-recorded videos to reduce their inclass cognitive load. This also allows more flexibility in terms of access to content and increases student participation and engagement beyond the classroom. Both have also gained some experience with online assessment - although mainly for formative assessment - such as the use of Blackboard quizzes to assess students' comprehension and identify misconceptions. Their interest in blended learning has led to their participation in the OER project, an institutional multi-year project aimed at understanding the breadth and depth of openness at the institution. Daniela, an academic staff developer, managed this project. Following the argument that openness is a practice, the aim of this project was to establish a community of practice (Wenger 1998; Wenger, McDermott and Snyder 2002) among lecturers - to provide a space for academic staff development, training, collaboration and sharing and as such to model and develop practices of openness. To achieve this eight so-called "OER pilots" were selected in 2016 and received funding to design, implement and measure the impact of OER (ethical clearance for this project was sought through institutional channels).

The eight OER pilots, including Bronwyn and Cheryl, were trained in the design and development of OER, such as training on the use of Creative Commons licensing. They met on a regular basis to share experiences and peer review their OER. Most lecturers originally 
decided to create screencasts or lecture recordings as supplementary teaching materials. These were shared on the institutional Learning Management System (LMS) Blackboard.

Participants of the OER project were interviewed by Daniela early in 2017 to share their experiences. The focus of the interviews was to establish the extent to which lecturers were engaged in OEP. However, since the protests were still fresh in participants' minds, the conversation in the interviews quickly veered to strategies to prepare or respond to past and future protests, the extent to which participating in the OER project had facilitated their academic development and on the ethics of continuing teaching during campus shut downs. These interviews, observations, and our ongoing conversations culminated in the write-up of two case studies (Merriam 1998) which describe Cheryl and Bronwyn's teaching practices and reflections through the times of disruption. As two of the few exceptions at the institution, both of them managed to complete the teaching of their courses and assessments during the times of disruptions. Although students were given the choice to complete the course online or come back for exams when campus opened up again early 2017, the majority of their students decided to complete the course online. In the next section we reflect on these case studies through Joan Tronto's Ethics of Care framework $(1993 ; 2013)$.

\section{REFLECTING ON OUR PRACTICES THROUGH TRONTO'S ETHICS OF CARE LENS}

\section{Attentiveness}

Tronto $(1993 ; 2013)$ purports attentiveness (caring about) to be noticing unmet needs and suspending one's own judgements and being able to see the world from the perspective of the one in need. In our reflections we perceived a high level of attentiveness on the part of the lecturers. Student protests started slightly later at our institution compared to the rest of the country, but when they happened campuses were shut down very quickly. Confronted with inaccessible classrooms Cheryl and Bronwyn's decision making processes around continuation of the academic project were based on ongoing student consultation, supported by social media and instant messaging tools such as WhatsApp groups. In a situation where the final decision about the continuation of the academic project was left to the individual lecturer, their choice to continue was based on a perceived need and willingness by a majority of students to complete the academic year. Cheryl for example mentions in her case study that:

"At the onset of \#FMF in 2016, with half of my curriculum still outstanding, students asked what would happen if classes were suspended. I suggested that online learning could be the solution." 
"While I empathise with the concerns raised by the \#FMF protesters, my feelings toward \#FMF were anger and disappointment. I did not agree with the intimidating manner in which \#FMF 'business' was conducted. I could not sit by and do nothing for my exit level students as I felt that their loss would be greater than the rest of the students. Although the danger of being 'caught' actively encouraging online learning could have swayed me to stop, I never felt personally threatened or that I was compromising any particular group of students by encouraging online learning. It was my belief to help those I could and enable them to do the same. ..."

Bronwyn in similar fashions reflects that:

"I obtained a general feeling from the majority of my students that they wanted to continue, and based on that I made the decision that we would continue. ... most important to me was I knew about individual cases, selected students in my classes who made substantial and very personal sacrifices to be able to graduate. ..."

\section{Responsibility}

Responsibility (caring for) is regarded by Tronto $(1997 ; 2013)$ as taking on the burden of responding to a need that was identified. Both lecturers not only saw the need to continue the academic project, they also took on the responsibility to adopt their current teaching and learning practices to design a learning environment conducive to the new context. It helped that both lecturers had previously acquired the necessary technical abilities from their own prior individual and shared teaching and learning endeavours. Bronwyn indicates that because of her personal relationship with her students, they informed her that they were willing to continue learning hence her quick decision to continue online. She describes her response as intuitive to the perceived need for continued learning online and naturally transited in an already established online space.

"... when the \#FMF occurred the first time, I did not take time to formulate a predetermined strategy that I would follow to 'move' my course exclusively online - I just did ....... at the onset of \#FMF in 2016 I had completed about 70\% of my curriculum in both of the two courses I was presenting at the time, for first year and final year students. When classes were indefinitely suspended, I continued teaching online. At the start of the protests, I had immediately created WhatsApp groups for both groups of students allowing continuous communication with my students. WhatsApp became the primary method to support communication, although all information was posted both on the LMS and on WhatsApp ...."

Cheryl as well used the last few days of face to face classes to consult with students and established processes to continue teaching and learning online in case access to campus was no longer possible, such as to regular check their online course on the institutional learning management system for direction. 
"I realised that since I already introduced blended learning to my students they would be able to continue in an online context with material such as narrated PowerPoint videos and guided designs. The work need to be presented in an organised manner as it would have been in class. An example includes referring to work by name or number, providing consistent naming conventions, etc. I envisioned developing three videos to address three sections of work. I developed a workbook containing multiple examples for each section of work as well as a project brief and laboratory brief. The smaller assessments were to be completed before the project and laboratory assessments. On the last day of class (unbeknown to me) before the campus shutdown, I supplied students with a copy of the design workbook and encouraged them to access the videos and any other material on Blackboard to complete the work. This proved to be the lifeline to their studies."

\section{Competence}

Competence (care giving) as defined by Tronto is being competent to care, which is always both a technical and a moral and political issue. Both lecturers and students' levels of competence were high, based on previous exposure and iterative, scaffolded introduction of blended learning and assessment. Blended and later online/open learning was neither new to the lecturers nor to their students. For both lecturers, upskilling themselves before \#FMF began was related to personal decisions to improve their own practice outside of the context of \#FMF. The fact that the first student protests occurred in 2015 served as impetus for them, both challenging themselves to improve their technical abilities and online teaching practices.

Part of both lecturers standard teaching practice was online engagement with students, thus students in their classes possessed the required level of competence as well. Consequently, when \#FMF began it was a relatively easy transition to exclusive online teaching for both lecturers and students. One example of how this was well translated into practices during \#FMF was Cheryl's set up of an anonymous blog during \#FMF 2016, which protected student identities but encouraged learning.

"I created an anonymous Blackboard blog to communicate with students if they had any queries about the learning material, and simultaneously respond to students' fears of personal repercussions for participating in the academic project. I constructed item headings in the blog for easy navigation, thus incidentally creating a repository of learning activities. From inception the blog was used and initial posts were less about work than about an exchange to reassure each other that continuing with the academic project would be okay. Studying online was a practical means of keeping busy while students waited to formally resume the academic project."

Both lecturers being part of the OER project was reassuring and helpful in terms of engaging their students online as Bronwyn comments on:

"Being a part of this community of practice has undoubtedly been an invaluable learning curve for me personally. Aside from expert knowledge gained on subjects that I would not have gotten elsewhere without a concerted effort, such as Creative Commons licenses, the experience of 
collaborating and sharing with like-minded enthusiasts further strengthened my confidence and quality of materials I was producing. Sincere and constructive criticism, and support offered by my OER colleagues was instrumental in my own professional development and personal growth. Without this experience, I would not have had the confidence to respond in the way that I did when \#FMF recurred at the end of 2016."

As an important factor both mentioned that they offered students choice. Cheryl made it clear from the onset that participation online was voluntary for students and also Bronwyn offered students choice in terms of assessment - students could choose between completing the course online before the end of the term or on campus when the new academic year started early 2017 .

\section{Responsiveness}

Tronto $(1997 ; 2013)$ explains responsiveness (care receiving) is listening to the response of the person/group that was cared for, sometimes resulting in new unmet needs. In our context, constantly adapting to the new learning context meant continuously shifting to new tools and technologies and even platforms, as the lecturers responded to students' feedback and levels of engagement, showing their responsiveness to students' needs. Moving from the institutional learning management system to more open, more accessible and more data effective platforms, was a necessary step to allow students to fully engage, as Bronwyn describes:

"I then produced a series of screencasts for both my classes. These screencasts were first made available to students on the LMS, however it soon became apparent that the cost of data was a serious constraint for students. In a move to mitigate this, I attempted using Google Drive with little more success than the LMS, also due to the limiting cost of data. Finally, in what I considered a brazen attempt to ensure as many students as possible had access to the screencasts I posted the material that I developed on YouTube. The feedback I received from students was positive, which encouraged me to continue this practice. The combination of WhatsApp chats, LMS discussions and YouTube screencasts enabled me to conclude the academic year for both classes."

Similarly Cheryl moved to WhatsApp as platform not only to communicate but also to share content to reduce her students' data consumption after noticing low participation rates online:

"Student's engagement was high at the beginning and dwindled once initial misunderstandings and open questions were resolved. However, as students used this tool anonymously it could not form part of their assessment portfolio. I was informed via the blog that the initial low online activity was due to financial constraints surrounding data. Students suggested WhatsApp as an option for disseminating learning materials. I re-recorded presentations using audio only, referencing the PowerPoint slides to reduce file size. Upon distribution on WhatsApp, there was an immediate spike in Blackboard activity, with increased Blackboard activity around the assessment submission dates."

The lecturer's willingness to repeatedly update materials based on students' feedback is another example of their responsiveness, as evidenced in Cheryl's case study: 
"The first design book video took 40 hours to produce. I attempted to create a product that would teach the concept covering all possible students' questions and concerns. During the online experience students articulated a range of misunderstandings which needed clarity and eventually I decided to create additional audio clips to address nuances in the students' understanding. I kept revising and re-issuing material according to additional student feedback with a final product issued after four weeks."

\section{Solidarity}

Tronto $(1997 ; 2013)$ offers solidarity (caring with) as taking collective responsibility, to think of citizens as both receivers and givers of care, and to think seriously about the nature of caring needs in society. In our reflection we recognised that ethics of our practices become a thorny issue when we look at Tronto's final element of solidarity. Solidarity speaks about collective responsibility and linking the needs of one's own context to the needs of society at large. As mentioned before Cheryl and Bronwyn's initial reasoning for continuing the academic project during protests was based on a feeling of responsibility towards the institution and their students, who seemingly did not challenge their decisions to continue teaching online. Continuing teaching this way was exhausting, as Cheryl notes, but also innovative and exhilarating:

"The online experience was intense in terms of commitment, physically exhausting in terms of time needed to prepare material and facilitate learning and also emotionally taxing as there was a greater awareness of the individual student's needs within a general climate of unsettledness, ambiguity and fear. I believe I was my best self online and I missed the frenetic energy of the online space."

However, what neither of the lecturers considered in their practice was the larger context their teaching took place in and what their actions in supporting the academic project online meant in relation to the underlying concerns of a student movement which stemmed from and highlighted the unequal access of students to resources.

Tronto warns in her work about the two dangers of care: paternalism and parochialism (Tronto 2013, 63). Paternalism is when a person in authority claims too much authority in a power relationship, thereby taking on too much responsibility. Ultimately the decision to continue with the academic project was taken by lecturers was guided by personal feelings towards the student protests, experiences and feeling of safety. Their immediate concern was to support their own group of students. They believed that the decisions they took were right for their group of students - they did not encounter strong student resistance and where they did, students could be persuaded to not disrupt the course. Bronwyn for example reflects: 
"I heard through the grapevine that some of my students were not happy with continuing teaching online, but they never came to me personally - even after I asked the class to let me know if there were any problems. And when it was time to write exams, they all turned up ...."

Brown $(2011,22)$ warns that "if online instructors do not use their positions of power to the fullest potential in support of a positive learning environment, those who are traditionally disadvantaged in our system of education face the same disadvantage when confronted with the online world". What if more students had demanded the academic project to stop and their voices had been stronger - would they have listened? Conjointly parochialism is defined as a person in authority setting the boundaries of their responsibility too narrowly. What are the effects of continuing an academic project on a micro level, a decision taken on a course by course basis, to the students' ongoing struggles across the country? Which needs did Bronwyn and Cheryl serve? Which needs should be served? The immediate needs of their students to complete their course or the needs of students across the country? Students who were prepared to risk everything to effect sustained change?

\section{TOWARDS MORE OPEN AND ETHICAL EDUCATIONAL PRACTICES AT THE INSTITUTION BEYOND TIMES OF DISRUPTION}

In this article we explore the ethics of two of the author's teaching practices against the backdrop of the recent \#FMF disruption at universities in South Africa in late 2016 and the role academic staff development plays in reflecting on the ethics of these practices beyond the protests. Typically blended learning during the academic year is supported by resources accessible on campus, such as free Wi-Fi and access to computer labs, which reduces some level of disparity in students' access to technology and consequently the delivery of the academic project. However in times of disruption the access to everyday resources is limited and the ethics of continuing the academic project through online and open learning is brought to the fore. What we miss in the discussion on the ethics of blended or online learning is a focus on nuance, context, relationship and practice. What we experienced over the last year were difficult conversations which left us with the frustration of not being able to provide answers. The more we spoke about our practices, the more we discovered the complexities and nuanced understandings, experiences and entangled relationships of lecturers and students involved.

Joan Tronto's work on the ethics of care $(1993 ; 2013)$ helped us navigate these difficult terrains. In particular her view that care is not a disposition but an active, on-going conversation and doing - an ethical practice resonated with us. Her suggestion that it is in our everyday practices of caring for ourselves and others that we most need to consider and practice ethical 
behaviour throws a new light on our teaching and learning practices. Through the five qualities of care we were reassured in our attentiveness, responsibility, competence and responsiveness towards our students. However, Tronto asks us to consider both the smaller and larger contexts the care relationship is set in. What we did not consider enough in our practice, is the larger context our practices are set in: our practices were not in solidarity with the larger student movement.

Her view that good care is not something that we can ever achieve, but that we can strive towards, allows us breathing space in our attempts as providing the best care possible to our students and us as she writes: "While perfection is impossible, improvement is not. Through good caring, people are better able to live well in this world" (Tronto 2001, 65). Also her insistence that care should be seen as a complex ethical relationship, in which all participants or actors who need to be involved, allows us to challenge current practices at the institution in terms how and who is in charge of the decision making process in times of disruption. No one person can be solely responsible for decision making in a caring relationship or web of relationships: All the parties involved should contribute to the discussion on caring needs and how they should be met (Tronto 2001).

Thinking through these difficult questions is not simple and simply not possible alone. As we came together and started to reflect on our shared practices we also started to engage with the ethics of what we were and are doing. Wenger, McDermott and Snyder (2002) argue that a community of practice embodies a certain way of behaving, a perspective on problems and ideas, a thinking style, and even an ethical stance. Can we as a group of academics pushing openness at the institution develop a shared ethical stance? A shared ethical practice? In this final section of the article we will make an argument that this ethical practice within the context of blended or open learning needs to address two main concerns: first concerns around student access and success and second to see our own practice as a political act.

Archer and Prinsloo $(2017,277)$ argue that providing openness per se does not necessarily "signify a more ethical stance, than, for example, limiting access". They emphasise that providing access is just a start and that an ethical open practice would be to ensure success of all learners. Essential considerations within an ethical practice would then for example be "a commitment ... to seeing students and users of resources in terms of inherently vulnerable human beings and not (just) as users of services/products and/or customers" (ibid., 281).

But thinking about access and success is not enough in our context - the decision to continue teaching was not just one based on technical issues, such as student access and digital literacies. Continuing and supporting the continuation of the academic project by means of blended or open learning must be seen as a conscious decision and a political act - both from 
the side of lecturers, students and academic staff developers. Ethical academic staff development cannot be limited to supporting academics in improving their teaching practices, in our case through the effective integration of technology in teaching and learning. Academic staff development, as Zembylas $(2017,2)$ highlights, needs to reflect on the ethics and politics of what we are doing unless we want to reproduce hegemonic systems of oppression our students fight so hard against:

"To the extent that 'improved teaching' is squeezed into categories of growth and progress grounded in discourses of teacher competences and behaviours - without instilling the practical demands of teaching life with ethical and political significance - then our efforts will unwittingly be caught up in a blind reproduction of hegemonic forms of educational development and monolithic notions of 'improved teaching' in higher education."

What does this mean for the practice of academic staff development? In our support of blended and open learning and the sharing of our practices during and after the protests, we cannot shy away from the uncomfortable questions around the ethics of our practices. While we believe in the importance of sharing our experiences and lessons learnt from teaching online during the protests widely we also need to raise questions around the conflict of interests and ethical dilemmas we found ourselves in. We might not have answers but we can create a space to reflect on these issues and challenge some of the individual, departmental and institutional decisions taken during the protest.

In reflecting upon our practices in retrospect we need to acknowledge that we had not considered the ethics of our practice during the \#FMF disruptions. Our later reflections however enabled us as "teaching practitioners" to learn from this experience about ourselves, our work, the way we relate to students and work, significant others, wider society and the culture of our society. It provided us with a foundation to consider new strategies to bring things out into the open, and frame appropriate and searching questions never asked before. Without this experience we would not have been able to explore and express our ideas on the experience both converging and diverging - as it would otherwise be difficult to communicate. We found that it challenged our assumptions and ideological illusions. From this position of discomfort we were compelled to consider damaging societal and cultural biases, continuing inequalities and question personal behaviours which perhaps silence the voices of others or otherwise marginalise them.

We thus suggest starting conversations around responses to future protests early, involving as many stakeholders as possible. There cannot be "business as usual" as long as student demands - in themselves often contradictory, complex and sometimes unexpressed - have not been met. How do we create a caring institution? Walker and Gleaves (2016) suggest that a 
"caring" institution is not made but rather developed by infusing institutions with caring pedagogies - bottom up. If institutional support is not in place lecturers need to form relationships and communities of practice to facilitate self-care and care for others - to be both caregiver and care receiver. The role of academic staff development must be in helping set up these spaces and facilitate these conversations. Allowing discomfort and ambiguity, vulnerability, "teacher conundrums" into these spaces is essential for academic staff development that is concerned with social justice (Zembylas 2017).

These spaces and conversations can have many forms, both formal and informal, regular and spontaneous, but must include student voices - heeding Tronto's advice, that it is the care receivers who know best what their needs are and how to respond to these. \#FMF has enabled a shift in the power relationships of students, lecturers and the institution. Student voices have been amplified and heard. This could enable a sustained shift in the care relationship, allocating responsibility for the academic project more equally between lecturers, students and the institution as a whole.

Thinking about the ethics of our practices involves the understanding that there are no easy right or wrong answers anymore, as Cronin $(2017$, n.p.) reminds us: "Use of OEP by educators is complex, personal, contextual, and continuously negotiated". Tronto's Ethics of Care framework allow us to see our practices as ever evolving and striving to be the best that we can be while negotiating the uncomfortable terrain of caring for self, our students and the society at large.

\section{REFERENCES}

Anderson, B. and M. Simpson. 2007. Ethical issues in online education. Open Learning: The Journal of Open, Distance and E-Learning 22(2): 129-38. doi:10.1080/02680510701306673.

Archer, E. and P. Prinsloo. 2017. Some exploratory thought on openness and an ethics of care. In Ethics in higher education research, ed. Divya Singh and Christoph Stueckelberger. Geneva, Switzerland: globethics.net. http://uir.unisa.ac.za/bitstream/handle/10500/21903/GE_Education_ Ethics_1_isbn9782889311644\%20(1).pdf?sequence=1

Bath, D. and J. Bourke. 2010. Getting started with blended learning. Brisbane, Australia: Friffith Institute for Higher Education. http://abekt.lib.ucy.ac.cy/synedria/17psab/17psab010a.pdf

Bozalek, V. G., D. Ng'ambi and D. Gachago. 2013. Transforming teaching with emerging technologies: Implications for higher education institutions. South African Journal of Higher Education 27(2): 419-436.

Brown, E. K. 2011. Safe spaces in online learning: The role of faculty perceptions in design and practice. Unpublished Doctoral Thesis. University of Georgia.

Brown, T. 2008. Ethics in eLearning. In iBiZ2008 Workshop for Net Business Ethics. Honolulu, Hawaii.

Centre for Innovative Educational Technology. 2016. CPUT Online Assessment Guide. https://docs.google.com/document/d/1yf1cKmNUik_naiv7Nvihe_woK_UJfwHJx4X1_gPWRM A/edit?usp=sharing

Coleman, P. D. 2011. Ethics, online learning and stakeholder responsibility for a Code of Conduct in 
Higher Education. Kentucky Journal of Excellence in College Teaching \& Learning 9(2011): 2934. doi:10.1017/CBO9781107415324.004.

Collins, J. 2016. "Exploration of online educators on questionable ethical practices of students: A qualitative study." Unpublished Thesis. Colorado Technical University.

Cox, G. and H. Trotter. 2016. Institutional culture and OER policy: How structure, culture, and agency mediate OER policy potential in South African universities. The International Review of Research in Open and Distributed Learning 17(5). doi:10.19173/irrodl.v17i5.2523.

Cronin, C. 2017. Openness and Praxis: Exploring the use of open educational practices in higher education. International Review of Research in Open and Distance Learning 18 (5): 15-35.

Czerniewicz, L., A. Deacon, M. Glover and S. Walji. 2016. MOOC - Making and Open Educational Practices. Journal of Computing in Higher Education. Springer US. doi:10.1007/s12528-0169128-7.

Gachago, D., E. Ivala, J. Backhouse, J. P. Bosman and V. G. Bozalek. 2013. Towards a shared understanding of emerging technologies: Experiences in a collaborative research project in South Africa. The African Journal of Information Systems 5(3): 94-105.

Fisher, B. and J. C. Tronto. 1990. Toward a feminist theory of care, $f d$, ed. E. Abel and M. Nelson, 3562. Albany, NY: SUNY Press

Gil-Jaurena, I. 2013. Openness in higher education. Open Praxis 5(1): 3-5.

Hanson, J. 2009. Displaced but not replaced: The impact of e-learning on academic identities in higher education. Teaching in Higher Education 14(5): 553-564.

McMahon, J. D. 2007. Ethical issues in web-based learning." In Ethical issues in web-based learning, 207-215. Idea Group Inc.

Meine, M. F., T. P. Dunn and R. Abbey. 2012. Ethical, academic, and practical considerations for online teaching: Does the search for quality and integrity come at the expense of academic freedom? Internet Learning 1(1). http://digitalcommons.apus.edu/internetlearning/vol1/iss1/6.

Merriam, S. B. 1998. Qualitative research and case study applications in education. San Francisco: Jossey-Bass.

Probst, B. 2016. Both/and: Researcher as participant in qualitative inquiry. Qualitative Research Journal 16(2): 149-158. doi:10.1108/QRJ-06-2015-0035

Reamer, F. G. 2013. Distance and online social work education: Novel ethical challenges. Journal of Teaching in Social Work 33(4-5): 369-84. doi:10.1080/08841233.2013.828669.

Tronto, J. 2013. Caring democracy. New York and London: New York University Press.

Tronto, J. 2001. An Ethic of Care. In Ethics in community-based elder care, ed. M. Holstein, P. Mitzen, 60-68. New York: Springer Publishing Company.

Tronto, J. 1993. Moral boundaries: A political argument for an ethic of care. New York \& London: Routledge.

Walker, C. and A. Gleaves. 2016. Constructing the caring higher education teacher: A theoretical framework. Teaching and Teacher Education 54: 65-76

Wenger, E. C. 1998. Communities of practice: Learning, meaning and identity. Cambridge: Cambridge University Press.

Wenger, E. C., R. McDermott and W. M. Snyder. 2002. Cultivating communities of practice. Boston, Massachusetts: Harvard Business School Press. doi:10.1016/j.jchas.2013.03.426.

Zembylas, M. 2017. Practicing an ethic of discomfort as an ethic of care in higher education teaching. Cristal - Critical Studies in Teaching and Learning 5(1): 1-17. doi:10.14426/cristal.v5i1.97. 